\title{
Tiempo kairológico y praxis histórica en el pensamiento de Ignacio Ellacuría
}

\author{
Kairological time and historical praxis in the thought of \\ Ignacio Ellacuría
}
Tempo kairológico e práxis histórica no pensamento de Ignacio Ellacuria

\author{
Dra. Marcela Brito de Butter* y Dr. Ulises Salomón Amaya**
}

\begin{abstract}
RESUMEN
El presente trabajo persigue analizar la temporalidad kairológica como modalidad del tiempo propio de la praxis histórica, entendida como dinamismo liberador y plenificador de la realidad histórica, a raíz de la necesidad de ahondar en esta dimensión de la obra del filósofo vasco-salvadoreño Ignacio Ellacuría. Para ello se realizará un diálogo con el aporte heideggeriano en torno a esta forma temporal, al no haber suficientes escritos ellacurianos en los que se discuta el problema del kairós y la historicidad. La tesis principal que se persigue en este diálogo radica en que la temporalidad kairológica es fundamental para entender las categorías de "civilización de la pobreza", "pobres con espíritu", "utopía" y otras categorías teológicas y políticas en la obra de Ignacio Ellacuría.
\end{abstract}

\section{SUMMARY}

This work seeks to analyze kairological temporality as a time modality typical of historical praxis, understood as a liberating and fulfilling dynamism of historical reality, as a result of the need
Palabras clave:

historicidad, tiempo kairológico, praxis, Ellacuría, Heidegger

\footnotetext{
* Salvadoreña, Doctora en Filosofía por la Pontificia Universidad Católica de Valparaíso, Chile. Catedrática e Investigadora del Departamento de Filosofía de la Universidad Centroamericana “José Simeón Cañas", El Salvador. Contacto: mbrito@uca.edu.sv ORCID: 0000-0002-5801-3301.

** Salvadoreño, Doctor en Filosofía por la Pontificia Universidad Católica de Valparaíso, Chile. Académico del Instituto de Filosofía de la Universidad de Antioquia, Medellín, Colombia. Contacto: ulises.amaya@udea.edu.co.

ORCID: 0000-0002-3361-4207
}

\section{Keywords: historicity, kairological time,}


to delve into this dimension of the work of Basque-Salvadoran philosopher Ignacio Ellacuría. This requires a dialogue borrowing from Heideggerian philosophy around temporal form, as there are insufficient Ellacurian writings in which the problem of kairos and historicity is discussed. The main thesis pursued in this dialogue is that kairological temporality is fundamental to understand the categories of "civilization of poverty", "poor with spirit", "utopia" and other theological and political categories in the work of Ignacio Ellacuría.

\section{RESUMO}

O presente trabalho busca analisar a temporalidade kairológica como modalidade do tempo próprio da práxis histórica, entendida como dinamismo liberador e plenificador da realidade histórica, devido à necessidade de intensificar nesta dimensão da obra do filósofo vasco-salvadorenho Ignacio Ellacuria. Para isso, será realizado um diálogo com o aporte heideggeriano sobre esta forma temporal, por não haver suficientes textos ellacurianos nos quais seja discutido o problema do kairós e a historicidade. A tese principal que se busca neste diálogo reside em que a temporalidade kairológica é fundamental para entender as categorias de civilização da pobreza, pobres com espírito, utopia e outras categorias teológicas e políticas da obra de Ignacio Ellacuria. praxis, Ellacuría, Heidegger

Palavras-chave: historicidade, tempo kairológico, práxis, Ellacuria, Heidegger 


\section{Introducción}

El pensamiento de Ignacio Ellacuría es de alta densidad y complejidad. Todavía, en la actualidad, continúa la discusión en torno al sentido articulador de toda su obra, dada la amplia variedad de temas que se abordaron en sus textos publicados hasta la fecha. Aunque no corresponde a este trabajo presentar todas las discusiones y posturas en torno a la evolución del pensamiento ellacuriano, sí es posible señalar que hay por lo menos cuatro líneas que han orientado el tipo de lectura de la obra de Ignacio Ellacuría: primero, una línea teológica; segundo, una línea de la filosofía de la liberación, así como una filosofía de la historia y una teoría crítica. Evidentemente, las ya enunciadas no son todas las claves de lectura que han surgido en los treinta años posteriores al asesinato de Ellacuría, pero sí es posible afirmar que estas se han constituido en las más influyentes a la hora de interpretar los conceptos fundamentales de la obra de nuestro autor.

La obra ellacuriana se caracteriza por articular la filosofía, la teología y la política, por lo que encasillar su pensamiento dentro de una sola rama de conocimiento implica empobrecer la interpretación de todos los demás conceptos, textos y problemáticas en las que se despliega su ingente obra. El abordaje de este trabajo es fruto de dos tesis doctorales en filosofía, las cuales versaron sobre la evolución filosófica de Ignacio Ellacuría, así como el aporte de Martin Heidegger a la interpretación de su pensamiento, respectivamente. La posición de la que partimos se fundamenta en el hecho de que la irrupción en el curso histórico actual que supone el acontecimiento de la salvación fue una preocupación central para Ignacio Ellacuría. Aunque en ciertos momentos de sus textos filosóficos, teológicos, universitarios y políticos abordó dicha cuestión, en ningún momento llegó a desarrollar el contenido de tal disrupción en el nivel de la persona como vehículo de la praxis histórica de liberación. Por esta razón, en estas páginas pretendemos abordar la estructura del acontecimiento de la religación y la temporalidad kairológica, además de la manera cómo podrían darse estos dos momentos de cara a la disrupción histórica de la salvación. Para esto, Heidegger proporciona pistas fundamentales, pues ni Zubiri ni Ellacuría alcanzaron a tocar los asuntos referidos a la forma cómo el ser humano puede abrirse a la transcendencia desde los límites de su estructura histórica. 
De ahí que nuestro trabajo persiga, principalmente, presentar la imbricación entre la estructura del tiempo histórico y la realidad humana, el carácter temporal del "acontecimiento" y el "tiempo kairológico" en la obra de Ignacio Ellacuría, puesto que ambas cuestiones conciernen a la forma en que se despliega la "realidad histórica" como categoría fundamental y articuladora de toda la obra ellacuriana, partiendo del supuesto de que la salvación es un momento capital de la plenificación histórica frente a la realidad del mal actual. En este sentido, aunque nuestras reflexiones se orientan por lo filosófico, también tocarán la dimensión político-teológica, porque la civilización de la pobreza y el hombre nuevo no se entienden sin el kairós vivido por la persona como criterio de discernimiento de la praxis histórica de liberación, pues Ellacuría no dedicó mucho espacio en su obra a desarrollar el problema específico del kairós, aunque aparece en sus trabajos dedicados específicamente al problema del tiempo histórico (Ellacuría $199020012009)^{1}$.

Por lo ya dicho, nuestro trabajo no tiene la pretensión de desarrollar una evolución intelectual de Ignacio Ellacuría, ni abordar las bases de su pensamiento o entablar discusión alguna con sus interlocutores, pues rebasa los límites de esta exposición y ya ha sido desarrollado en otros artículos (Brito 2020a 2020b; Samour 2020a 2013 2016). Sin embargo, consideramos que es valioso que la propuesta de lectura que aquí perfilamos rompa con las lecturas que persiguen casar a la fuerza a Ignacio Ellacuría con Zubiri, Hegel o Marx a la hora de exponer su pensamiento, pues su filosofía madura tiene la suficiente fuerza para erigirse por sí misma e iluminar la realidad histórica en la que nos situamos. El problema de la temporalidad kairológica, además, es un tema que no se ha tratado en ningún artículo filosófico hasta el momento, debido sobre todo a las lecturas que reducen el abordaje filosófico de Ellacuría a lo dicho por Zubiri, a la filosofía de la historia, la filosofía de la liberación, la actividad exclusivamente teológica, entre otras. La cuestión de la apertura histórica a la transcendencia es una cuestión pendiente que aquí proponemos abordar.

1 Véanse: Filosofía de la realidad histórica (Ellacuría 1990), capítulo primero; el artículo "Persona y comunidad" (Ellacuría 2001) y el curso "El sentido del hacer histórico" (Ellacuría 2009). 
Nuestra propuesta de análisis se desplegará en tres momentos: en la primera parte, situaremos la "realidad histórica" como eje categorial del pensamiento de Ignacio Ellacuría, para, en segundo lugar, situar el problema de la temporalidad propia de la realidad histórica y la religación como experiencia de apertura a la transcendencia y, por tanto, momento disruptivo de la historia. Esto nos conducirá en el tercer momento a plantear, desde la interpretación heideggeriana del kairós y su disposición de parousía, de qué forma puede darse en la persona la disrupción de lo divino, de cara al problema del horizonte de la civilización de la pobreza como propuesta para la articulación de una teoría y una praxis de carácter emancipador para las mayorías oprimidas, no solamente del momento histórico en el Ellacuría vivió y murió, sino también para el mundo actual.

\section{La "realidad histórica" como categoría articuladora del pensamiento de Ignacio Ellacuría}

Iniciaremos abordando, en líneas generales, la estructura de despliegue de la realidad histórica, la cual se subtiende sobre lo ya planteado en la cosmología zubiriana. Aunque este último no es el foco de este estudio, sí vale la pena tener en cuenta que lo que Ellacuría retoma de su pensamiento, a grandes rasgos, es una nueva idea de "filosofía", el problema de la historicidad humana como acontecimiento y el concepto de religación, los cuales ya estaban contemplados en alguna medida durante sus primeros años de formación (Samour 2012). Para Ellacuría, la "realidad histórica" se define por ser la máxima envolvente de lo real y, con ello, queda actualizada como la forma de realidad más alta $^{2}$, lo cual quiere decir que:

...la realidad histórica, ante todo, engloba todo otro tipo de realidad: no hay realidad histórica sin realidad puramente material,

2 Ellacuría explicita el despliegue de la "realidad histórica" como objeto filosófico en cinco tesis: primero, la realidad histórica apunta a la idea de que la realidad intramundana constituye una unidad física de carácter diferenciado; segundo, que el dinamismo de dicha realidad intramundana es intrínseco, sistemático y estructural; tercero, que el dinamismo dialéctico es uno más entre los diversos dinamismos que configuran a la realidad histórica, por lo que las tesis del hegelianismo, el marxismo o el materialismo dialéctico engelsiano quedarían invalidadas al pretender aplicarse a la totalidad de lo real; cuarto, este dinamismo abierto es un proceso de realización de lo real, es decir, de carácter ascendente y enriquecedor de lo real; finalmente, la realidad histórica, al desplegarse, sería el objeto último de la filosofía, por su carácter englobante, totalizador y, por ello, forma suprema de realidad (Ellacuría 1990 30-43). 
sin realidad biológica, sin realidad personal y sin realidad social; en segundo lugar, toda forma de realidad donde da más de sí y donde recibe su para qué fáctico - no necesariamente finalístico- es en la realidad histórica; en tercer lugar, esa forma de realidad que es la realidad histórica es donde la realidad es "más" y donde es "más suya", donde también es "más abierta" (Ellacuría 1990 43).

La idea de realidad histórica asume en sí misma la idea de "realidad" de Zubiri, cuyo carácter estructural e intrínsecamente dinámico posibilita que, desde sí misma, vaya dando paso a formas más complejas y novedosas de realidad. Esta consideración de la realidad permitió a Ignacio Ellacuría considerar a la "realidad histórica" como objeto filosófico, pues lo que acontece a lo histórico afecta a la índole entera de la realidad (Zubiri 1995 272-273; Ellacuría 1990 43). Dicha conceptualización sobre la unidad estructural y dinámica de lo real, elevada en el ámbito histórico, posibilita comprender de forma más radical el rol que juegan la realidad humana y la praxis en la configuración, dinamización y totalización de lo real. En el ámbito histórico, lo político, lo social, lo religioso y lo cultural (en sus momentos individual y colectivo) adquieren una densidad metafísica novedosa, al entrar de lleno en la estructuración de la unidad de la realidad histórica.

Por lo anterior, el análisis de las estructuras de lo real, asumidas en el ámbito histórico, no puede quedar relegado a un plano meramente teórico. La "realidad histórica", como forma de realidad de carácter dinámico y abierto, posibilita articular la dimensión metafísica de la realidad con los ámbitos teológico y político, siendo estos últimos los que permiten explorar, de forma complementaria y profunda, las posibilidades de una irrupción histórica que vehicule la transformación de las coordenadas históricas actuales a unas más ricas y humanizantes.

\section{Estructura del dinamismo histórico en la "realidad histórica"}

La conceptualización de la realidad histórica como objeto propio de la filosofía ellacuriana comprende un despliegue muy concreto, porque asume toda otra forma de realidad y sus dinamismos, dándoles 
una nueva totalización y dinamismo unitario radicalmente novedoso, según sean las posibilidades apropiadas por los pueblos en el proceso histórico. Lo anterior implica que formas de realidad, como la materia, el espacio, el tiempo, la vida, el ser humano y la historia, así como sus respectivos dinamismos, quedan positivamente envueltos y potenciados. Asumidos en la forma de "realidad histórica", su forma de despliegue dinámico es de carácter estrictamente procesual y temporal. Desde esta conceptualización de lo histórico, es posible apuntar al problema de la índole de la irrupción kairológica y el problema del acontecimiento como momento de despliegue del "más" de realidad o del novum propio de la transcendencia histórica. Esta última debe ser entendida no como "transmundización", sino como absolutización del ámbito histórico desde la praxis.

Es en el orden estructural y metafísico de la realidad histórica donde lo real se abre a sus más ricas posibilidades porque, aunque la realidad da de sí misma desde su carácter de poderosidad (Zubiri 1988), la liberación de sus máximas posibilidades solamente se da por la actividad intelectiva de la esencia abierta. La realidad humana es la que abre el ámbito histórico y, por lo tanto, debe entrar en la consideración estructural de la historia para evitar los reduccionismos idealistas que criticó en su momento X. Zubiri. Ellacuría asumió esta tesis en su propia idea de filosofía y en su propio sistema metafísico (Ellacuría 2001). Asimismo, resulta valioso señalar que, sobre las ideas de "realidad" y "estructura", así como esta crítica a los reduccionismos, nuestro autor también retomó por lo menos tres aspectos más que son relevantes para las reflexiones que aquí ofrecemos: el dinamismo constitutivo de toda forma de realidad; el carácter estructural de las realidades sociales e históricas y el carácter fundamental de la persona, y el problema de la religación como apertura a la poderosidad de lo real desde la experiencia personal históricamente situada. Este último aspecto, desde nuestra consideración, es fundamental si se quiere entender la importancia de la irrupción kairológica en el cambio de rumbo civilizatorio, que fue una preocupación central en el trabajo de Ellacuría. Esto nos conduce a la cuestión de cómo, desde la intramundanidad de la historia, es posible dicha apertura. Por tal razón, nos adentraremos en la estructura material-temporal de la realidad histórica para llegar a la cuestión del tiempo kairológico y el carácter personal de la vivencia de dicha irrupción. 


\subsection{Las dimensiones material y temporal de la historia}

La consideración sobre la realidad histórica en la filosofía de Ignacio Ellacuría se funda en la conceptualización zubiriana sobre la realidad, pues esta última se comprende como aquello que es formalmente de suyo. Es una unidad estructural de notas de carácter abierto y dinámico, es decir, respectivo (Zubiri 1985 1998). En virtud de su carácter estructural, la realidad no es mera sustancialidad o adición de momentos, sino constitutiva sustantividad unitaria y estricta. Lo que caracteriza a la sustantividad, según Zubiri, es ser sistema de notas cuyo dinamismo es procesual y, por tanto, tiene radical independencia y actualidad respecto de las demás realidades, en y por sí misma. En consecuencia, el mundo se funda en esta unidad de respectividad de todas las cosas reales en este orden de constitución (Zubiri 1995). No obstante, no puede comprenderse cómo se dinamiza la unidad total de la realidad intramundana si no entra de lleno la consideración concerniente a la realidad humana, sobre la cual se subtiende la realidad histórica. Aunque Ellacuría asume las principales tesis zubirianas sobre la realidad y el dinamismo, como hemos señalado en el apartado previo, no es menos cierto que nuestro autor radicaliza y lleva a sus últimas consecuencias esta forma de comprender la realidad, pero desde el ámbito de lo histórico:

Pero el hallazgo radical de Zubiri en "Sobre la esencia", reside, a juicio de Ellacuría, en la idea de realidad entendida como esencia y desde la esencia, en el caso de la realidad humana, haber encontrado el modo de radicar, respetándolas en su respectivo carácter, lo que hay de naturaleza y lo que hay de historia en la realidad que es una. A juicio de Ellacuría, no se trata de una conciliación y menos de una mera yuxtaposición, sino de una profundización que lleva a Zubiri a transformar la idea misma de esencia para que en forma coherente y unitariamente pueda ser en su caso naturaleza e historia (Samour 2021 85).

La realidad histórica, como envolvente de cualquier otra forma de realidad, tiene una dimensión material desde cuyo dinamismo emergen y se apoyan las demás dimensiones, en un proceso paulatino de complejización cada vez mayor. Es por esta razón que, como señala Samour, no es posible hablar de una separación dual entre naturaleza e historia, realidad e inteligencia. Esta unidad se apoya en el carácter 
material y dinámico de la realidad, pues es unidad sustantiva dinamizada en una diversidad de momentos que se subtienden los unos sobre los otros en el orden de su suficiencia constitucional. La materia es la dimensión en la que se funda el dinamismo de lo real, pues es "unidad de elementos en estado constructo, de modo que cada elemento tiene una determinada 'posición' dentro del sistema, una posición que no es mera 'colocación', sino que es efectiva posición espaciotemporal-dinámica" (Ellacuría 1990 52). Esto implica que la actualidad de lo real solo es posible en virtud de su constitución material, sin llegar a confundir materia con corporalidad (aunque la corporalidad o somatización sea una de las formas de presencia de las cosas reales). Asimismo, es este carácter material el que se constituye en principio de formalización, estructuración y dinamización de todas las cosas reales, incluida la inteligencia (Zubiri 1998 191-194).

Por lo ya dicho, podemos sostener que, en virtud del principio de diversidad de lo real que se funda en la materia, las cosas reales adquieren su dinamismo concreto de acuerdo con la índole de su propia estructura. Este dinamismo se expresa en la espacialidad de lo real, no como a priori kantiano sino como forma de estructurarse dicho dinamismo, porque la cosa, como unidad de sustantividad, se constituye por ser unidad posicional de notas. En dicha unidad, cada nota adquiere su funcionalidad en respectividad de las demás y de su propia posición sistemática; es así como las cosas que constituyen el ámbito mundanal tienen su funcionalidad y dinamismo respectivo de acuerdo con su posición y espacio propios. Las acciones o efectos secundarios a la realidad de la cosa no son añadidos extrínsecos, sino expresión y exteriorización de su propia constitución (Id. 62-69). Esto es fundamental para entender de qué manera la realidad va dando de sí y cómo emergen dinámicamente la realidad personal y el tiempo kairológico.

La temporalidad propia de cada cosa, según Ellacuría, queda apoyada en su forma propia de "dar de sí", y esto afecta la índole del sistema sustantivo entero: el de la cosa y el de la realidad intramundana. Desde esta perspectiva, el tiempo no se reduce a su forma cronométrica, sino que es fundamentalmente cronología, porque el carácter procesual del dinamismo funda el orden del decurso en que las cosas van realizándose: antes-ahora-después. Cada cosa se dinamiza en este orden de transcurrencia, de lo contrario, su realidad no sería viable, dado que 
las notas de la estructura no pueden actualizarse todas de cualquier manera o en cualquier momento temporal. Las cosas reales no tienen tiempo, sino que son tempóreas y cada una tiene su peculiar manera de transcurrir y dar de sí, según sea su propia estructura: “[m]ás bien son las cosas con su peculiar procesualidad las que determinan la peculiar respectividad del tiempo [...] De aquí se sigue que cada transcurso tiene su tiempo propio y que la estructura real de los procesos impone a la línea temporal una estructura distinta, según sea la índole de los procesos" (Ellacuría 1990 86).

Lo afirmado por Ellacuría nos indica que el tiempo mundanal no es una suma de las formas temporales de cada cosa real, pero su transcurrencia no permanece incólume porque toda la unidad es dinámica y expresa este dinamismo en las cosas reales. De la forma de dinamizarse las diversas formas de realidad pende la índole del dinamismo de la estructura total, esto es, de la realidad en cuanto tal. Esto le confiere radical importancia al problema de la realidad humana, puesto que esta es la que determina fundamentalmente el tipo de orden totalizador de lo real por su modo de ser real (Id. 43), y este modo de totalización es, justamente, lo histórico no como mera forma temporal sino como forma de realidad. Lo apuntado hasta el momento son insumos claves para analizar la temporalidad kairológica, aunque esta, lo veremos en breve, necesariamente se subtiende sobre el carácter abierto de la realidad humana.

\subsection{La estructura del tiempo kairológico}

El kairós es una modalidad temporal definida como "momento oportuno" o "momento propicio" en el dinamismo temporal de la realidad, tanto por su dimensión individual como sistémica pues, desde el planteamiento ellacuriano, esta estructura temporal está apoyada en una configuración muy precisa de las notas que constituyen la unidad sustantiva de la realidad histórica. Es decir, no cualquier momento ni cualquier realidad pueden posibilitar que haya un momento de irrupción radicalmente novedoso en el ámbito histórico.

El kairós tiene su plena concreción cuando su dinamismo queda asumido en la estructura del tiempo histórico. Precisamente por esta razón la praxis juega un papel fundamental en la configuración del sistema de posibilidades en el que se apoya la liberación kairológica 
de la innovación y plenificación de la realidad en el ámbito histórico. La praxis, desde la perspectiva de Ellacuría, puede entenderse en cuatro sentidos distintos: como totalidad del proceso social en el orden de la transformación de la realidad natural y social, como unidad de todo lo hecho en el cuerpo social en orden a su propia transformación, como dinamismo total e inmanente de la realidad histórica, y como todo aquello que el hombre realiza de cara a su propia realización personal (Ellacuría 1991 110-113). Los distintos sentidos que cobra la praxis revelan el carácter fundamentalmente cuasi creador que tiene la acción humana en el ámbito histórico. Sin embargo, no cualquier acción, en cualquier momento, supondrá necesariamente una praxis. Esta supone condiciones propias, a nivel individual y colectivo, y que haya un momento propicio que libere el poder de lo real que opera en la estructura del sistema de posibilidades de la respectiva altura histórica:

La praxis histórica es ella misma principio de realidad y principio de verdad en grado supremo. Es principio de realidad en cuanto en ella, integralmente entendida, se da un summum de realidad; es principio de verdad, tanto por lo que tiene de principio de realidad como porque la historización de las formulaciones teóricas es lo que, en definitiva, muestra su grado de verdad y de realidad (Id. 112).

Si el kairós es momento propicio, entonces la altura histórica debe estar estructurada de modo tal que la procesualidad de todas las estructuras y fuerzas históricas puedan dar paso a ese acontecimiento liberador, cuyo carácter innovador es "más": más rico, más real y más suyo, pues su liberación pende de una apropiación optativa de unas posibilidades por encima de otras, previamente ofrecidas en un sistema. La irrupción del kairós por la vía de la praxis, además, solo es posible por estar subtensionada sobre la realidad humana. El phylum, como vector material de la historia, posibilita la innovación histórica porque el carácter sentientemente abierto de la inteligencia abre la realidad a su dimensión transcendental, sin agotar lo que la realidad es y puede dar de sí (Pintor Ramos 1996 34). La realidad no se agota porque es, desde sí misma, más de lo que se presenta en sus contenidos a la inteligencia, pero también es más de lo que está actualmente en su manifestación actual. La realidad de las cosas, así como la personal, no se reduce a su talidad: es más que sí misma, pero en y desde 
sí misma. Esto es el momento del dominio de lo real actualizándose en la totalidad de lo real, constituyéndose en un exceso desde sí mismo. Esto es poder, y su dominio se realiza en el apoderamiento de la persona en el orden de la constitución de su propia realidad (Zubiri 1988 86-87).

Esta realización y este apoderamiento implican que el momento kairológico necesariamente debe estar posibilitado estructural e históricamente porque, aunque la realidad sea exceso y poder, el proceso creacional sobre el que se apoya la historia no es creatio ex nihilo. Sin la materialidad de la realidad o la aprehensión primordial de esta no habría transformación: las posibilidades son de la realidad, pero son para el hombre, por el trato que tiene con las cosas (Samour 2002b 236-237). La temporalidad propia del kairós, como despliegue del poder de lo real, pende de la situación humana ante las cosas y de su ofrecimiento como posibilidades que vehiculan un poder que, en su carácter innovador, puede liberar tanto a la persona como a la altura histórica en la cual se encuentra situada.

Por tanto, el kairós se constituye en un momento de toda la estructura temporal de la historia, pero se puede considerar que la misma es tiempo "propicio", porque implica una convergencia de las formas de temporalidad en las que se dinamiza tanto la vida humana como la historia: pasado-presente-futuro. El "ahora" se actualiza como momento del futuro, pero positivamente apoyado en el pasado, que persiste como posibilidad desde la cual lanzarse al futuro (Ellacuría 1990 85). Por esta apoyatura temporal, hay continuidad histórica en el nivel estructural y hay apertura a la novedad del futuro, porque es la índole de la estructura lo que ha sido y lo que hay en el presente como posibilidad, lo que crea el sistema posicional y la respectividad entre las distintas formas de realidad que la constituyen. En este sentido, cada momento histórico posibilita, según su propia configuración, el "cuándo" y lo propicio que compete al kairós, en función de la sincronía de los tiempos de la unidad histórica: "No se trataría ya de una pura simultaneidad de eventos en un mismo tiempo, sino de una sincronía de los tiempos mismos de cada uno de los procesos" (Ibíd.).

El kairós se constituye así en una modalidad de despliegue del tiempo histórico, cuyo contenido o momento de "dar de sí" es radicalmente innovador respecto de las demás estructuras, precisamente 
por estar subtensionado sobre estas. Lo fundamental de esta forma de temporalidad es que su forma concreta de apertura es más radical porque, en la medida en que se vehicula por la praxis, debe necesariamente acontecer en la realidad personal y colectiva, por lo que la persona queda abierta a sí misma, desde sí misma, desde su pasado hacia el futuro (Id. 82). Esta apertura repercute en la configuración de la altura histórica, así como en el sistema de posibilidades en el que ha ido realizando la realidad personal y socialmente comprendida. Desde esta forma de comprender el tiempo histórico en esta modalidad, queda clara la relevancia de la irrupción histórica por la vía de la praxis para cambiar la forma de totalización de la realidad que ha configurado la civilización actual.

Por lo anterior, la apropiación individual cobra relevancia en la configuración personal y en la constitución de una realidad absolutamente relativa. Esto no solamente afecta, sin embargo, a la realidad personal individual, sino también al cuerpo social, porque lo obrado, al ser disrupción, queda incorporado al cuerpo social por afectar potencialmente la estructura histórica (Id. 510). Es así como las voliciones, tendencias y acciones personales se incorporan al ámbito histórico y repercuten en su configuración, pues, al liberar y crear libremente nuevas formas de realidad, también abren nuevas posibilidades de configuración de la vida y los destinos de las colectividades. Esto es posible porque la apertura a la transcendencia histórica desde la persona se da por la vía de la experiencia de la religación, que veremos a continuación.

\subsection{El kairós y la religación}

Lo histórico, pues, queda configurado por dos dimensiones de un mismo proceso: la transmisión tradente de posibilidades. Este dinamismo también compete a la estructura material de la historia, pero también a su dimensión formal: en la primera está referido a la entrega de la estructura material específica en el ser humano, que compete al phylum como vector material de lo histórico, porque de no haber humanidad, no habría historia (Id. 496). En y por el phylum es que se transmite, por entrega del código genético, el carácter de animal de realidades a todos los nuevos individuos de la especie humana. Y es que, a juicio de Ellacuría, no puede obviarse que la novedad histórica va de la mano 
con la novedad de la especie, que se encuentra positivamente apoyada en la innovación que compete a la estructura material de la realidad. Lo específico en el ser humano radica en la nota de inteligencia que le constituye en un híper animal: híper por encontrarse radicalmente abierto en su modalidad de enfrentamiento, en la cual la realidad queda aprehendida como de suyo, por lo que la afección tónica y el momento de respuesta serán también reales (Id. 185-198).

Esta apertura es externa en lo referido a su acción sobre el medio, pero también es interna, interior e íntima, porque el individuo humano queda radicalmente abierto a $s u$ propia realidad. Por su esencia abierta, filéticamente recibida, el ser humano puede constituirse en persona (Gudiel 78). No obstante, aunque en el carácter abierto de la inteligencia se posibilite desde la unidad psicorgánica una aprehensión, volición y sentir también abiertos, la apertura personal a la propia realidad también requiere de lo que sea entregado por la tradición: la manera cómo se hará personalmente la propia realidad pende de las capacidades, dotes y posibilidades de las cuales se dispongan en cada momento histórico (Ellacuría 2009 131). La realidad personal no se construye en solitario, sino que es constitutiva con otros, con las cosas, con la realidad. En convivencia, desde este estar con, vivir con y hacerse la vida con, se afirma la posesión de sí mismo en cada uno de los actos. En este sentido preciso es que la vida humana se realiza personalmente, reafirmándose en su Yo, su ser sustantivo (Zubiri 1988 30-31).

La configuración de la realidad personal es lo que constituye la vida en un relativo absoluto, porque supone la afirmación de la propia realidad apoyándose realmente en lo real. Dicha apoyatura se realiza principalmente por la inteligencia; solo de esta manera puede abrirse al poder de lo real y ser vehículo de este (Gudiel 115). Zubiri considera que lo fundamental de la vida personal radica en que su forma es algo que se va dando a sí misma, por ello es inquietud: a cada momento y con cada uno de sus actos y decisiones, se juega la forma entera de la realidad personal. $Y$ esto no es una finalidad, sino una actitud, que es la forma como todos los actos y decisiones van a hacer de cada cual su propia realidad de tal o cual manera. En este sentido, la vida es misión: la de hacerse la vida según el carácter de lo que se quiera ser (Zubiri 1988 34). Precisamente por esto, Ellacuría señala: 
De ahí la gravedad de la vida personal, en la que se pone en juego la realización del hombre como persona. El sentido de nuestras decisiones absolutas frente a cualquier realidad cobra así una doble importancia: en cuanto es decisión, compromete nuestra autonomía, y en cuanto es tal decisión, en cuanto se encarna en un acto determinado, configura irremisiblemente la figura de determinadas posibilidades con menoscabo de nuestro ser. Ninguno de estos actos se perderá. No sólo porque decantará unas de otras, sino porque habrá configurado nuestro propio ser personal (Ellacuría 2000 70-71).

La vida se configura según una actitud radical, apoyada en la realidad como fundamento desde el cual el ser humano va dándose una determinada figura a su realidad personal. Es en y por la actitud radical que, apoyándose en la realidad, el ser humano es lanzado a esta misión de hacerse la vida. Este "ser lanzado" por el poderío de la realidad, tiene una forma con triple dimensión: ultimidad, posibilidad e impelencia (Zubiri 1988 37-38). La realidad es fundamento, posibilidad e imposición sobre la vida humana, porque le remite, en su estarse constituyendo, a algo más allá de sí misma y, a su vez, a constituirse en algo más de lo que ya se es. Esta actitud radical por la cual la vida va cobrando su forma y se absolutiza relativamente y se afirma en este exceso, es la religación:

Sólo apoyado y fundado en este fundamento último el hombre puede acceder a la riqueza de posibilidades de la realidad para su vida, al ser la posibilidad de todas las posibilidades (...) Hay un acceso a la realidad del fundamento en la apertura intelectiva a la realidad, no saliendo de la realidad de las cosas, sino sumergiéndonos en ellas radicalmente. En esta dimensión profunda de las cosas, el poder del fundamento fundamentándolas, es un poder que puede apoderarse de la persona y ser vehiculado por ella, según sea la forma propia de la realidad personal. Por la índole constitutiva de la persona, la experiencia de la religación es histórica, porque en ella "se va perfilando de modo gradual y firme la 'figura de la deidad"' (HD 157) (Gudiel 2006 107-108).

Esta modulación de la realidad personal es posibilitada y a la vez refluye sobre la altura histórica, por ser ambas realidades con una temporalidad propia cuya transcurrencia se configura por la praxis 
y las posibilidades que, como hemos visto, se apoyan en el carácter de poderosidad de lo real que funda la posibilitación como forma de respectividad a la vida humana que tiene este poder: "De suyo la religación afecta al hombre no separadamente de las cosas, sino que en alguna forma afecta a todo. Pero sólo en el hombre es formalmente religación, sólo en él es el acontecer formal de la fundamentalidad" (Zubiri 1988 92). La religación tiene carácter experiencial, no es un hecho concluso que se da de una vez por todas, porque pone de manifiesto el carácter enigmático del poder de lo real, cuyo contenido no es dominable, conceptualizable ni instrumentalizable, pero que posibilita que la persona pueda reconfigurar su vida y el momento histórico en el que vive para enriquecer y liberar. Las cosas y la realidad no son dos realidades separadas, sino dos momentos que manifiestan una sola experiencia religante que se actualiza en la realidad humana. Por esto la praxis que se funda en el absoluto relativo de la persona, requiere de una opción radical por el fundamento en su concreción histórica, la cual no es coyuntural ni ocasional, sino perenne, por ser la vida misión e inquietud:

La voluntad de fundamentalidad es intrínsecamente opcional como lo es la voluntad de no fundamentalidad. Hay realidades que se me pueden presentar y aún se presentan inexorablemente como realidad-fundamento. No se trata sólo del caso de Dios o de un innominado poder de lo real; se trata también de casos como los de relación personal e incluso de casos que pudiéramos llamar colectivos, por ejemplo, el caso de las mayorías populares o de los pobres, en la teología de la liberación. Puede, en primer lugar, que una realidad-fundamento no se me presente claramente como tal por presiones ideologizadas; en segundo lugar, puede que se me presente como tal, pero que yo la reduzca deliberadamente a realidadobjeto (...); pero, en tercer lugar, puedo deliberadamente aceptar la realidad-fundamento como realmente fundamentante de mi ser entero (Ellacuría 2000a 125).

El carácter de opción que tiene la fundamentación de la vida personal a través de la experiencia de la religación es lo que permite liberar la realidad, pues su actividad es fruto de una opción. Asimismo, el estar realizándose la vida religadamente implica que esta se renueva, es lugar de irrupción del kairós a nivel personal, pero también es 
posibilidad de irrupción en la realidad colectiva a través de la praxis de la persona (Ellacuría 2007 532-533). Precisamente, por esta razón decíamos más arriba que el carácter de momento propicio del kairós depende tanto de las estructuras históricas en sus dimensiones colectiva y personal. La religación abre así la posibilidad de romper o alterar el curso histórico para constituirlo en verdadera irrupción creadora y liberadora, que vehicule el cambio histórico de la actual altura procesual, configurada por el signo del mal histórico, también denominada por Ellacuría como "civilización del capital". La cuestión problemática de la experiencia de la religación y la irrupción kairológica es su contenido, pero también la forma como la persona puede alcanzar dicha experiencia. Esto es algo que Ellacuría no dejó apuntado, ni tampoco Zubiri, y es aquí donde entra el aporte heideggeriano para iluminar esta cuestión y entender con mayor claridad la raíz de la experiencia personal y colectiva de liberación.

\section{El tiempo kairológico como tiempo vivencial}

El tiempo kairológico nos coloca de una manera radicalmente distinta respecto del resto de la estructura del tiempo humano. Si bien guarda relación con el tiempo de la psique, el tiempo kairológico revela al ser humano dentro de su cotidianidad, lo que significa que no refiere primariamente a una teorización sobre el tiempo, sino a la experiencia de éste en y desde la vivencia humana; de ahí que deba hablarse de temporeidad antes que de temporalidad. El kairós, además, no solo nos remite a esa experiencia del tiempo, sino que nos muestra que esa experiencia está apoyada en una forma determinada de estar en la realidad y el mundo, y dado que el ser humano se encuentra en el mundo de un modo determinado, a saber, históricamente, el tiempo kairológico se fundamenta en el carácter histórico de la realidad humana. Así, en esta modalidad del tiempo presenciamos una incardinación entre el tiempo de la vida y el tiempo histórico (Espinoza Lolas 288); por ello, podemos afirmar que existe una relación constitutiva entre el tiempo kairológico y la historicidad humana.

Como se ha mencionado, Ellacuría no realiza un análisis sistemático ni una problematización de esta modalidad del tiempo y, por ello, es necesario retomar planteamientos que nos permitan comprender cómo opera la temporalidad kairológica en el pensamiento 
ellacuriano. Sin duda, para habérnosla con esta dificultad es inevitable que la figura del maestro de Ellacuría, Xavier Zubiri, aparezca como el pensador por antonomasia con quien el pensamiento ellacuriano debe entrar en discusión. Sin embargo, nos parece necesario sacar a Ellacuría de este binomio, y explorar la posibilidad de que entre en diálogo con otros pensadores que permitan identificar problemáticas en su filosofía o que puedan brindarnos elementos que las clarifiquen. Es por esta razón que utilizaremos algunos de los aportes relacionados con el tiempo kairológico de Heidegger ${ }^{3}$. Y es que, si bien Zubiri realiza un análisis sistemático del tiempo, no aparece en ese análisis una reflexión en torno al tiempo kairológico. La relación entre Heidegger y Zubiri ha sido ampliamente estudiada, y la importancia del pensador de la Selva Negra en el pensamiento zubiriano es innegable, por lo que consideramos que no debe resultar extraño que Ignacio Ellacuría pueda entrar en diálogo con el mago de Meßkirch. Muchos son los lugares comunes entre Ellacuría y Heidegger, como los que hay entre Zubiri y Heidegger, lugares cuyo análisis escapa de la pretensión de nuestro trabajo. Sin embargo, estimamos importante dejar señalada esta cuestión antes de abordar las cuestiones fundamentales en torno al tiempo kairológico.

\subsection{Ellacuría: apuntes sobre el tiempo kairológico}

Dada la complejidad del problema que abordamos y la breve extensión de nuestro trabajo, consideramos pertinente realizar una serie

3 No es arbitrario retomar algunos elementos heideggerianos en la construcción de un marco que nos permita abordar el tiempo kairológico en Ellacuría, pues Heidegger no es un filósofo ausente en su pensamiento. En su tesis doctoral "La principialidad de la esencia en Xaxier Zubiri", de 1965, podemos encontrar la influencia de ciertas ideas heideggerianas en la sección tercera, al analizar la índole formal del acto de intelección desarrollada en el apartado titulado "no es ser desvelación". Otros textos en los que también se encuentran estas ideas son artículos como "Existencialismo ateo", de 1968; “Cinco lecciones de filosofía de Xavier Zubiri", de 1965, y en la correspondencia que mantuvo con su viceprovincial, el P. Luis Achaerandio: aquí, Ellacuría da cuenta de las entrevistas con Zubiri, cuya pretensión era justificar el deseo de trabajar con y sobre él, pero, además, se evidencia que Heidegger era un tema de conversación y discusión recurrente con Zubiri. Asimismo, una lectura concienzuda de la obra ellacuriana nos revela la presencia de ciertos planteamientos heideggerianos en su obra filosófica y teológica, porque dos de los grandes maestros de Ellacuría, Zubiri y Rahner, estuvieron profundamente influenciados por Heidegger. Sobre esta relación ha habido ya mucha investigación, por lo que es imposible que esta influencia no haya llegada también a Ellacuría (véase Espinoza Lolas 2007; Pintor Ramos 1994; Conill 2003; Cornejo 2010-2012; Rivera 2001; Vorgrimler 1990; Schickendantz 2008; Law 2000). 
de apuntes que permitan esbozar un marco de comprensión para un posterior análisis sistemático. En este sentido, dos son los elementos fundamentales de nuestro análisis: por un lado, una determinada disposición fundamental que Heidegger llama "estar-vigilante", que caracteriza el "estar a la espera" de algo que está por venir o la parousía. Dicha espera, contrario a lo que podría pensarse, no nos remite al cuándo de esa reaparición de Cristo sino al cómo, por lo que esa espera es la praxis de la vida fáctica misma. La praxis aparece como algo fundamental que posibilita la apertura a dicho acontecimiento, de ahí que el "estar" de esta experiencia temporal sea la espera y la disposición en la que se está en ella sea el "estar-vigilante" (wachsam sein). Por otro lado, la parousía que se presenta como aquello que está por venir opera como un horizonte de comprensión y sentido que, a pesar de no estar aconteciendo en el "ahora", opera ya como algo que configura la subjetividad y la praxis del ser humano; por ello, dicho acontecimiento supone, desde ese "aún-todavía-no", una ruptura e irrupción histórica epocal que, aunque no está aconteciendo, ya es un elemento operativo. De ahí que esta temporalidad sea más que un tiempo oportuno o tiempo propicio, aunque se apoye en las estructuras de la realidad de las cuales emerge este carácter propicio.

\subsubsection{La dimensión temporal de la utopía y el profetismo}

Ellacuría, tal como se ha mencionado, no realiza un análisis sistemático de esta modalidad del tiempo histórico. Las referencias a ella en su obra filosófica son muy puntuales y escasas, de ahí la necesidad de aproximarnos a su obra teológica para encontrar más elementos que posibiliten la comprensión del tiempo kairológico. En su artículo "Utopía y profetismo desde América Latina. Un ensayo concreto de soteriología histórica" (1989) hay elementos fundamentales que nos permiten comprender mejor la temporalidad kairológica en el pensamiento ellacuriano. La utopía y el profetismo aparecen en Ellacuría como elementos históricos, lo cual busca enfatizar no solo su carácter transcen-

4 Heidegger analiza el tiempo kairológico, especialmente en Einführung in die Phänomenologische der Religion del semestre de invierno de 1920/1921. En esta obra realiza una interpretación de las Epístolas de San Pablo, que se centra en el análisis de la temporalidad propia de la vivencia del cristianismo de las primeras comunidades. Heidegger señala que el tiempo nuevo, kairós, es una experiencia del tiempo vital y personal y, por tanto, no es objeto de medición alguna: escapa de cualquier tipo de control. 
dental sino también inmanente. La transcendencia no se ubica como algo externo al mundo, sino que éste, en su inmanencia, aparece como el lugar en el cual y desde el cual dicha transcendencia acontece. Este carácter de inmanencia, además, es lo que revelará el carácter "carnal" de ambos momentos, y es que para Ellacuría es el "acontecimiento encarnado", el Verbo que se hace historia, lo que muestra el vínculo inexorable entre eternidad-transcendentalidad y temporalidad-inmanencia (Ellacuría 2000 233).

La utopía y el profetismo no solo refieren a un mundo, sino a un lugar específico dentro de él. Este locus posee una serie de características que reclaman como urgente ambos elementos, al estar atravesado por una negatividad histórica. De ahí que, en este locus, utopía y profetismo acontezcan como un "esperar y 'esperanzar' contra todo juicio dogmático que cierra el futuro del proyecto y de la lucha” (Id. 234). Así, al hablar de utopía y profetismo nos referimos a una vivencia específica de la historia y del tiempo ${ }^{5}$. Según Ellacuría, en la profecía se manifiesta el carácter temporal de dicha vivencia, dado que esta se refiere a un presente en el cual convergen pasado y futuro, $y$, dado su acentuado carácter vivencial, el profetismo transparenta el carácter de "ahora" en la medida en que parte de una situación histórica concreta, y es futuro por su carácter anunciativo configurado a partir de una utopía que, según Ellacuría, es historia y metahistoria a la vez: es un ahora y un futuro en el cual el reino de Dios se operativiza (Id.235). Ellacuría sostiene que ello permitiría afirmar que existe cierto nivel de homologación entre el reino de Dios y la utopía.

Así, la concreción de la utopía es aquello que permite el advenimiento del reino de Dios en la historia, ya que es lo que posibilita su historización ${ }^{6}$. En esa medida, la utopía va configurando una nueva subjetividad y un nuevo modo de estar en el mundo, lo cual redundará

5 En este sentido, Heidegger señala que el kairós es una experiencia específica del tiempo vital y personal, lo cual implica la imposibilidad de su medición o control, experiencia que está determinada por una relación fundamental con Dios. Producto de ello es la comprensión de la eternidad desde dicha vivencia y la configuración de un nuevo comportamiento cristiano.

6 Para Heidegger, el kairós está estrechamente vinculado con la experiencia de la parusía, es decir, un acontecimiento que aparece en un horizonte por venir, y de ahí que esta experiencia del tiempo tome el carácter de una espera expectante que oscila entre dos momentos tensivos: un 'ya', referente a la primera venido de Cristo, momento eminente fáctico e histórico, y un 'todavía-no', que refiere a la segunda venida de Cristo que 
en una reconfiguración de las estructuras históricas que posibilitan al ser humano habérselas con el mundo, la alteridad, y consigo mismo. De esta manera, la discusión en torno a la utopía no refiere a la presencia o no del reino, sino a la historización de éste que ella refleja. Ahora bien, esta concreción solo es posible debido al carácter ejecutivo del profetismo: “...se entiende por profetismo la contrastación crítica del anuncio de la plenitud del reino de Dios con una situación histórica determinada" (Id. 237); es decir, existe un vínculo entre la transcendencia del Reino y su dimensión histórica, de ahí que se haya señalado que se trata de una trascendencia inmanente, siendo esta relación la que posibilita la contrastación que, según Ellacuría, es constitutiva del profetismo. Y es que, debido a ese carácter transcendente, las limitaciones de nuestra inmanencia, en su dimensión histórica, se hacen manifiestas. La contrastación deviene de esta manera en una vivencia capaz de "prenunciar el futuro e ir hacia él" (Id. 238): esta contrastación, que es la vivencia histórica del profetismo, remite a una vivencia determinada del tiempo, porque ese anuncio de algo que está por venir, orientación hacia el futuro, implica un modo particular de habérselas con ese anuncio, dicho modo es el de una "espera" (Ibid.), es decir, un "ahora". Dicha "espera" no se refiere, de ningún modo, a un estar en pasividad frente a esa negatividad histórica que ha aparecido como tal en la contrastación profética; se trata de un "esperar activo"7, un "esperar" cuya pretensión es la construcción histórica de aquello que está por venir, es decir, esa espera guarda un vínculo esencial con la praxis, en este caso en concreto, con la "praxis cristiana". En virtud de lo ya dicho, Ellacuría advierte que:

Si la utopía no puede ser realmente utopía cristiana sin el profetismo que la inspire, tampoco el profetismo será realmente cristiano sin la animación de la utopía. El profetismo cristiano vive de la utopía cristiana, la cual, en tanto que utopía vive más y se alimenta de la interpelación que hace el Espíritu a través de la historia, pero en

irrumpirá 'nuevamente' de manera histórica. Por lo tanto, no se trata de la presencia de Cristo, sino de la reaparición de aquel que ya es un aparecido (Heidegger 2006 131).

7 Heidegger señala que el tiempo kairológico, si bien se caracteriza por una espera (Erwartung), ésta no es una espera pasiva, sino se trata de un estar-vigilante de la segunda venida del Mesías. De ahí que esta experiencia del tiempo fuese una tribulación absoluta. La espera es así tensa, vigilante y activa, es decir, la espera es actividad, ejecución, praxis. 
tanto que cristiana vive más del anuncio de la promesa explícita e implícitamente expresa en la revelación ya dada (Id. 239).

De esta manera, es evidente el vínculo constitutivo que existe entre la utopía y el profetismo: aquella marca un horizonte capaz de configurar el "ahora", el otro permite operativizar dicho horizonte en ese "ahora". Asistimos así a una vivencia de la temporalidad en la cual se experiencia una co-pertenencia entre historia y transcendencia (Id. 241).

\subsection{El tiempo kairológico y los "pobres con espíritu"}

La pobreza y los pobres es uno de los temas transversales de la obra ellacuriana, lo cual significa que es uno de los temas que más se ha trabajado de su pensamiento, por lo que es fundamental señalar algunos aspectos que son relevantes para comprender la relación que existe entre los "pobres con espíritu", el profetismo y la utopía en la vivencia de la temporalidad kairológica. Se ha señalado que una de las características fundamentales del vínculo entre profetismo e historia es la "espera" ${ }^{8}$. Este esperar es una "espera activa", de ahí el carácter práxico de ella. Esta "espera" se operativiza en un modo determinado de estar y habitar el mundo, que nuestro autor denomina "pobres con espíritu" . Ellacuría sostiene que los pobres no son solo los materialmente pobres, hay que serlo también espiritualmente: con ello se refiere a un modo determinado de vivenciar la pobreza. Esta comprensión ellacuriana de la pobreza se aleja de aquella que comprende al pobre como aquel que acepta pasivamente un destino frente al cual no tiene más opción que la resignación. Se trata entonces de una vivencia que incorpora espiritualmente la pobreza y con ello la conciencia de la

8 Frente a la pregunta por la parusía, Pablo responde, dice Heidegger, refiriendo al cómo y no cuándo de esa espera, de ahí que el acento de la experiencia del tiempo kairológico se encuentre en la vivencia fáctica-histórica y no en la experiencia trascendente de Dios: "Por ella ("estemos vigilantes") vemos que la cuestión del "cuándo" se retrotrae a mi comportamiento. Como la $\pi \alpha \rho o v \sigma i ́ \alpha$ está en mi vida, ésta remite al ejercicio de la vida misma" (Heidegger 2006 132).

9 En una ponencia titulada "Los pobres, 'lugar teológico' en América Latina", dictada el 6 de septiembre de 1981 en el marco de un Congreso sobre "Teología y pobreza", y publicada posteriormente en la revista Misión Abierta (4-5), del mismo año, Ellacuría realiza un análisis de la dimensión espiritual de la pobreza y, luego de explicar los cuatro elementos que dicha espiritualización posee, finaliza afirmando que existe una imperiosa necesidad de los "pobres con espíritu". 
negatividad de su situación, y en este darse cuenta de ella comprende también las posibilidades propias, el compromiso frente a ellas y frente a la negatividad que lo ha sumido en la pobreza (Id. 255). En definitiva, se trata de un pobre que deviene en un sujeto histórico y de una "espera" que deviene "esperanza", que opera como dinamismo de la utopía y que permite que el "pobre con espíritu" sea capaz de iniciar el proceso de transformación de la realidad a partir de la vivencia en el "ahora" de los valores que esa utopía implica. Así, en el acontecer del "pobre con espíritu”, el futuro aparece configurando el modo cómo el pobre habita el mundo en su presente.

No se trata del cálculo fijo, que lleva a invertir con la calculada perspectiva de unos resultados deseables a plazo determinado, ni se trata tampoco de un sueño idealista que saca de la realidad, sino, más bien, de la aceptación de la promesa liberadora de Dios, una promesa fundamental, que lanza a un éxodo, en el cual se conjugan propósitos y metas históricas con seguridades transhistóricas (Id. 256-257).

$\mathrm{Y}$ es que el aspecto fundamental de la temporalidad kairológica no se trata del "cuándo", sino del "cómo" se vivencia la "espera". El "pobre con espíritu", entonces, no solo refiere a un sujeto de liberación, sino también a una determinada disposición en el mundo, y es que esta disposición anuncia ya en el "ahora" lo que se espera. El "pobre con espíritu" implica un compromiso con la transformación de la realidad negada, que se expresa como realidad de pobreza e injusticia. Así, su compromiso con la lucha contra todas aquellas condiciones que fueron configurando esa negatividad implica una nueva configuración de la subjetividad. De esta manera, el "pobre con espíritu" se refiere a una experiencia determinada de conversión y a un nuevo modo de relacionarse con la alteridad con la cual se identifica, y se reconoce como co-partícipe de una experiencia reveladora y renovadora del mundo. El "pobre con espíritu", así entendido, implica una vivencia individual y colectiva, porque si la pretensión es subvertir la historia, realizar lo anunciado en la utopía del reino (que no es solamente la utopía de la tierra nueva), ello conlleva una radical liberación: la praxis, para ser histórica y lograr la transformación histórica, ha de ser colectiva, una praxis colectiva que no es solo con los otros, sino también para los otros. Esta subversión y liberación no implican que esto acontezca en 
un futuro por venir, ya que, dada la relación entre profetismo y utopía, los pobres con espíritu "experimentan" ya esa liberación en el "ahora". Por ello es posible que este "pobre con espíritu" se haga cargo de la realidad, cargue con la realidad y se encargue de la realidad desde una determinada vivencia de la temporalidad. Y es que la importancia de la discusión sobre la temporalidad no radica solo en la relación que ésta tiene con la historicidad, sino en el modo cómo determina la praxis política del ser humano.

Ese espacio es el recorrido por los pobres con espíritu en una nueva disposición cristiana, que lleva a dar la vida por los otros, de modo que en esa entrega, la encuentren al encontrase a sí mismos; que lleva a poder despreciar todo el mundo, cuya conquista para nada importa, si supone la pérdida de sí mismo, del espíritu de uno mismo (Mc 8, 34-38 y par); que lleva a vaciarse de sí mismo para, tras el vaciamiento, reencontrarse de nuevo, en la plenitud de lo que se es y de lo que se puede ser (Flp, 1-11) (Id.257).

La praxis es, de esta manera, una revelación del tiempo; sin embargo, esto no significa que ésta acontezca en el tiempo, sino que refiere a la apertura del tiempo mismo. La praxis temporaliza el tiempo con una temporalidad que le es propia, pues implica cierta ruptura de la historia, algo que se observa sobre todo cuando ésta opera como una "praxis liberadora", una conmoción de los individuos y la irrupción de nuevos mundos que ya están contenidos en ella como pre-mundos, estas características particulares y constitutivas de la praxis son las que nos revelan al kairós (Vatter y Ruiz Stull 18). Dado el carácter vivencial del kairós es que se encuentra vinculado a una situación particular, pero no a cualquier tipo de situación, sino a una situación oportuna, telúrica, una situación de roturas y de irrupciones. De ahí que la "praxis histórica de liberación" sea el lugar, que es un no-lugar, en que se manifiesta transparentemente la temporalidad kairológica.

Pero hay otro 'cuándo' más importante, que va más allá de las 'fechas' y que significa la posición de una cosa respecto de otra en la serie de modulaciones cualitativas de onda temporal. Ha sido una experiencia permanente y profunda en muchos pueblos: hay tiempos de penitencia, las cosas tienen su kairós, tienen su oportunitas, etc. (Ellacuría 1990 84). 
Así, el tiempo kairológico remite a un quiebre, al advenimiento de algo nuevo que llega a instaurar un nuevo orden de cosas. De ahí que sea considerado como un tiempo de oportunidad, de cambios y "conversiones" que inauguran un nuevo espíritu epocal que parte de la experiencia interior de determinados acontecimientos y momentos decisivos; es decir, el kairós remite a la vivencia íntima de la temporalidad, vivencia que, a pesar de ser íntima, rompe cualquier tipo de solipsismo del sujeto y se manifiesta en la praxis histórica del ser humano.

\section{Conclusiones}

El análisis y las reflexiones realizadas hasta el momento nos llevan, al cierre de la presente investigación, a señalar algunas conclusiones preliminares.

En un primer momento, debemos señalar que existen diversas lecturas acerca de la obra de Ignacio Ellacuría que, aunque permiten generar una primera aproximación a su pensamiento, tienen el defecto de encerrar o forzar el tipo de interpretación que puede darse a sus trabajos cuando se analizan como conjunto. En este sentido, es importante para cualquier estudioso conocer las fuentes de la filosofía de Ignacio Ellacuría en una etapa formativa inicial, pero no resulta fructífero que haya obligatoriamente en todo ejercicio hermenéutico la mención de Xavier Zubiri, Karl Marx o G. W. F. Hegel, pues implica coartar la posibilidad de diálogo con otros filósofos y corrientes. Cualquier investigación y problematización de un filósofo debe ser un esfuerzo por desentrañar, desde el núcleo mismo de su pensamiento, las posibles lecturas que de este se puedan desprender.

En el caso de Ignacio Ellacuría esto es más notorio, porque son pocos los esfuerzos por estudiar su pensamiento desde sí mismo, y no en referencia a los filósofos de cabecera con los cuales dialoga en múltiples trabajos. La complejidad de su sistema filosófico supone una exigencia académica, pero también ética, de desentrañar la potencia que le es propia, a fin de poner de relieve su radicalidad y novedad en el marco de la filosofía producida en América Latina, pero también de la tradición filosófica de la cual él también es heredero. Nuestra postura, a lo largo de este trabajo, ha perseguido un enfrentamiento netamente con él y no con Zubiri ni con Heidegger, aunque ambos filósofos proporcionan fundamentos y pistas de lectura que renuevan las posturas 
tradicionales sobre su filosofía, que ha solido entenderse como una de orden segundo, por ocuparse de elementos parciales de la realidad (filosofía de la liberación, teología de la liberación, filosofía de la historia, teoría crítica, decolonialidad). Que puedan desgajarse estas lecturas de su pensamiento es una consecuencia natural de su sistema filosófico y de su propia idea de "filosofía".

En esta misma línea, en segundo lugar, hemos considerado fundamental articular un diálogo con Heidegger, precisamente porque los aspectos referidos a la manera como el ser humano abre su inmanencia a la trascendencia en términos concretos, es algo que ni Zubiri ni Ellacuría alcanzaron a abordar, por las circunstancias de sus respectivos fallecimientos. No se debe pues a que hubiera un desconocimiento por parte de ambos filósofos del aporte heideggeriano, y esto es observable en un análisis profundo y detenido de la totalidad de sus obras, así como al hecho de que los tres son pensadores cuya forma peculiar de comprender la filosofía se desgaja de la novedad de la idea de "filosofía" que pudo articular Edmund Husserl. Tanto Heidegger como Zubiri y Ellacuría son un vivo ejemplo de que todo sistema parte de una idea de "filosofía", por lo que el diálogo e influencia mutua se enraíza en esta cuestión y no en una interpretación arbitraria de sus obras.

Además de lo ya señalado, comprender la dimensión transcendental de la realidad en el pensamiento de Ignacio Ellacuría y su conexión con las problemáticas soteriológicas y escatológicas, supone la posibilidad de vislumbrar su novedad superadora respecto de la filosofía zubiriana. Ellacuría nunca se limitó a repetir lo ya dicho por Zubiri, sino que partió de una apropiación situada y con intereses claros que le permitieron llevar estos planteamientos a sus últimas consecuencias, lo cual se concretó en su propia filosofía y sistema metafísico. Por tal razón, la lectura que hemos esbozado, de la mano del aporte de Martin Heidegger, no supone que este le dará más rigurosidad a aquel, sino que posibilitará otras líneas de lectura que iluminarán dimensiones del pensamiento ellacuriano que muchos académicos no han abordado hasta el momento, porque no abandonan las lecturas que se instalaron durante las décadas de 1990 y 2000 . Desentrampar la lectura zubiriana, marxiana, hegeliana, de teoría crítica y otras más sobre el pensamiento de Ellacuría es, a nuestro juicio, una labor pendiente. 
Como tercer momento, consideramos que el análisis de la temporalidad kairológica, la religación, la praxis histórica de la liberación y la salvación son cuestiones que ponen de relieve la capitalidad del vínculo entre filosofía y teología en el pensamiento ellacuriano. En su sistema y sus escritos, la una no se supedita a la otra, sino que son dos dimensiones que operan y evolucionan conjuntamente en el análisis de la realidad. La filosofía no puede hacer a un lado a la teología, y viceversa, si se quiere comprender a cabalidad el legado de nuestro autor, pues se corre el riesgo de cercenar los elementos teóricos y estructurales fundamentales de su sistema, así como de mistificar y distorsionar el carácter revolucionario, compasivo y radical de su aporte. En su teología aparecen cuestiones que no se desarrollan en su filosofía, y en esta última están los elementos estructurales sobre los que se apoya el análisis teológico, pues ambas dimensiones se ocupan del mismo problema. La cuestión vital radica en discutir cuál es la idea de "filosofía" de la que parte Ellacuría, y qué entiende por su objeto, su estructura, dimensiones y dinamismo, con el fin de lograr un análisis más abierto, que no coarte lo que la filosofía ellacuriana puede dar de sí.

Estas consideraciones nos llevan a señalar un cuarto punto, referido a la praxis histórica de la liberación, la cual se ha interpretado en otros autores y obras como accionalidad de carácter estrictamente político, pero sin analizar cómo repercute en la salvación histórica al liberar la transcendencia desde la inmanencia. Nuestra lectura ha sostenido que la praxis es radical porque, aunque es política, también tiene una dimensión teologal y, por esta razón, el tiempo de la praxis histórica de liberación es el tiempo kairológico. Aunque Ellacuría no desarrolló el contenido de esta modalidad temporal, en sus textos es posible localizar suficientes elementos que posibilitan deducir que la temporalidad de la praxis se apoya en la temporalidad kairológica, en la medida en que la apertura y disrupción de la novedad liberadora están vehiculadas por la liberación del plus de lo real que le compete a la idea ellacuriana de praxis. En este sentido, podemos hablar de un dinamismo estructural en el que ambos momentos se coimbrican, dinamizan y liberan en el ámbito de la realidad histórica.

La praxis histórica de liberación va de la mano con la utopía, la salvación histórica y el anuncio del reino de Dios, por lo que obviar el problema de la temporalidad kairológica supone un serio impedimento 
para la comprensión de esta preocupación central en el pensamiento de Ignacio Ellacuría. Por tanto, consideramos fundamental el acercamiento con el aporte heideggeriano como clave de lectura para iluminar esta dimensión que, además, posibilita el diálogo entre el filósofo vasco-salvadoreño con otros autores y problemas. Desde este esfuerzo, hemos intentado darle la correspondiente relevancia a la dimensión teológica para profundizar y enriquecer el análisis filosófico del pensamiento de nuestro autor, para quien nunca hubo tal escisión. Esto, a nuestro juicio, permitirá un diálogo interdisciplinar fundamental para alumbrar otras posibilidades de comprensión, análisis y transformación de nuestro momento histórico actual, en el que la soledad, la pérdida de sentido, el egoísmo y el miedo son lo que más se apodera de las vidas de los más pobres y necesitados, a quienes Ignacio Ellacuría se comprometió a servir con su obra, espíritu cristiano, pensamiento y praxis histórica de liberación.

\section{Bibliografía}

Brito, M. "El objeto de la filosofía de Ignacio Ellacuría: la realidad histórica como propuesta metafísica". Estudios 2020: Especial: Profesores de Estudios Generales investigan - Dossier: Ignacio Ellacuría: su vida y su labor académica. Universidad de Costa Rica, 2020a. DOI: 10.15517/RE.V0I0.40938

Brito, M. “Génesis y evolución de la categoría realidad histórica en Ignacio Ellacuría. Realidad: Revista de Ciencias Sociales y Humanidades, 155 (2020b): 17-46. DOI: https://doi.org/10.5377/ realidad.v0i155.10383.

Cataldo Sanguinetti, Gustavo. El instante: Kairós y temporalidad kairológica en Martin Heidegger. S.L: S.N, S.F. Recuperado de https://www.academia.edu/10329505/El_instante_ Kairós_y_temporalidad_kairológica_en_Martin_Heidegger

Conill, Jesús. "Heidegger y Zubiri”, Revista Portuguesa de Filosofía 59/4 (2003): 1181-1202.

Cornejo Ojeda, Juan Patricio. "Introducción a la lectura del texto El hombre y Dios de Xavier Zubiri", The Xavier Zubiri Review 12 (2010-2012): 33-46; reproducido también en Revista Realidad 132 (2012): 295-314.

Ellacuría, Ignacio. Cursos universitarios. San Salvador: UCA Editores, 2009. 
Ellacuría, Ignacio. Escritos filosóficos. Tomo 3. San Salvador: UCA Editores, 2001.

Ellacuría, Ignacio. Escritos teológicos. Tomo 1. San Salvador: UCA Editores, 2000a.

Ellacuría, Ignacio. Escritos Teológicos. Tomo 2. San Salvador: UCA Editores, 2000.

Ellacuría, Ignacio. Filosofía de la realidad histórica. San Salvador: UCA Editores, 1990.

Ellacuría, Ignacio. Veinte años de historia en El Salvador (1969-1989). Escritos políticos. Tomo 1. San Salvador: UCA Editores, 1991.

Espinoza Lolas, Ricardo. "En torno al problema del tiempo de la realidad humana en el pensamiento de Zubiri", Pensamiento 63/236 (2007): 267-302.

Gudiel García, H. La fe según Xavier Zubiri: una aproximación al tema desde la perspectiva del problema teologal del hombre. San Salvador: UCA, Departamento de Teología, 2006.

Heidegger, Martin. Contribuciones a la filosofía (Del acontecimiento). Traducción de Breno Onetto Muñoz. Valparaíso: Proyecto posdoctoral Fondecyt № 3990020, 1999-2002.

Heidegger, Martin. Die Grundprobleme der Phänomenologie. GA 24. Frankfurt: Klostermann, 1975.

Heidegger, Martin. El evento. Buenos Aires: El hilo de Ariadna, 2016.

Heidegger, Martin. Interpretaciones fenomenológicas sobre Aristóteles. Indicación de la situación hermenéutica [Informe Natorp]. Madrid: Editorial Trotta, 2002.

Heidegger, Martin. Introducción a la fenomenología de la religión. Madrid: Ediciones Siruela, 2006.

Law, David R. “Negative Theology in Heidegger's Beitrage zur Philosophie", International journal for Philosophy of Religión 4/3 (2000): 139-156.

Másmela, Carlos. Martin Heidegger: el tiempo del ser. Madrid: Trotta, 2000.

Nicólas, Juan Antonio y Espinoza Lolas, Ricardo (eds.). Zubiri ante Heidegger. Barcelona: Herder, 2008.

Pintor Ramos, Antonio. "En las fronteras de fenomenología: la noología de Zubiri”, Cuadernos salmantinos de filosofía 21 (1994): 245-284. 
Pintor-Ramos, Antonio. Génesis y formación de la filosofía de Zubiri. Salamanca: Universidad Pontificia de Salamanca, 1983.

Pintor-Ramos, Antonio. Xavier Zubiri (1898-1983). Madrid: Ediciones del Orto, 1996.

Rivera, Jorge Eduardo. Heidegger y Zubiri. Santiago, Chile: Editorial Universitaria, 2001.

Romano, Claude. El acontecimiento y el mundo. Salamanca: Ediciones Sígueme, 2012.

Romano, Claude. Lo posible y el acontecimiento. Introducción a la hermenéutica acontecial. Santiago, Chile: Ediciones Universidad Alberto Hurtado, 2008.

Samour, Héctor. “Zubiri y la filosofía de la liberación”. Realidad: Revista de Ciencias Sociales y Humanidades 87 (2002a): 371-392. DOI: https://doi.org/10.5377/realidad.v0i87.4139

Samour, Héctor. "La propuesta filosófica de Ignacio Ellacuría”. Teoría y praxis (2013): 52-67. Recuperado de http://hdl.handle. net/10972/957,

Samour, Héctor. "El legado filosófico de Ignacio Ellacuría”. ECA: Estudios Centroamericanos 71/744 (2016): 33-50.

Samour, Héctor, "Filosofía y libertad". En Ignacio Ellacuría. «Aquella libertad esclarecida», En: R. Alvarado y J. Sobrino (eds.). San Salvador: UCA Editores, 1999. 103-145.

Samour, Héctor. Crítica y liberación: Ellacuría y la realidad histórica contemporánea. Valencia y Madrid: ADG-N Libros y Universidad Carlos III de Madrid, 2012.

Samour, Héctor. Voluntad de liberación: el pensamiento filosófico de Ignacio Ellacuría. San Salvador: UCA Editores, 2002b.

Schickendantz, Carlos. "La relación entre Martin Heidegger y Karl Rahner. Una recepción y diferenciación todavía por escribir", Teología y Vida 49/3 (2008): 371-397.

Valencia García, Guadalupe. Entre cronos y kairós. Las formas del tiempo sociohistórico. Barcelona: Anthropos, 2007.

Vatter, Miguel y Ruiz Stull, Miguel (eds.). Política y acontecimiento. Santiago, Chile: FCE, 2011.

Vorgrimler, H. “Der Tod als Thema der neuren Theologhie”, Teologische Berichte 19 (1990): 13-64.

Zubiri, X. Sobre el problema de la filosofía y otros escritos (1932-1944). Madrid: Alianza Editorial, 2002. 
Zubiri, Xavier. El hombre y Dios. Madrid: Alianza Editorial-Sociedad de Estudios y Publicaciones, 1988.

Zubiri, Xavier. El problema filosófico de la historia de las religiones. Madrid: Alianza Editorial-Fundación Xavier Zubiri, 1993.

Zubiri, Xavier. Estructura dinámica de la realidad. Madrid: Alianza Editorial-Fundación Xavier Zubiri, 1995.

Zubiri, Xavier. Inteligencia sentiente/Inteligencia y realidad. Madrid: Alianza Editorial-Fundación Xavier Zubiri, 1998.

Zubiri, Xavier. Inteligencia y razón. Madrid: Alianza Editorial-Fundación Xavier Zubiri, 1983.

Zubiri, Xavier. Naturaleza, Historia, Dios. Madrid: Alianza EditorialSociedad de Estudios y Publicaciones, 1987.

Zubiri, Xavier. Sobre la esencia. Madrid: Alianza Editorial-Sociedad de Estudios y Publicaciones, 1985. 